\section{Manual de organização}

Por A. R. François. Rio de Ja. neiro, Ao Livro Técnico, 1972. $236+$ XII p. ilustrado. Trad. de Nivaldo Maranhão Faria do original francês Manuel d'organization du travail. 1969. v. 5 (Coleção Administração e Gerência).

Ao resenhar este livro, notamos, logo de início, a omissão, tanto na capa da brochura quanto nas páginas introdutórias, de uma parte do título que aparece no original francês: "1..$^{\circ}$ volume: organização do trabalho". Tal falha é agravada na ficha catalográfica, onde o livro é classificado como "organização industrial", já que, na nossa opinião, 136 deveria permanecer como está no original, "organização do trabalho".

No prefacio, A. Nogueira de Faria, presidente da ABTA, recomenda o livro com as seguintes palavras:

"O Manual de organização, de A.R. François, apresenta de forma concisa e bem sistematizada 0 know-how de organização mínimo e necessário para que as empresas possam sobreviver, especialmente as média e pe- quena empresas, que precisam encontrar meios para defender o seu reduto mercadológico, em face da investida dos Conglomerados e Empresas Multinacionais que dispõem de capital, influência política e excelente assessoramento na área de Organização e Métodos" (grifos do autor do prefácio).

"E também aconselhado aos jovens Técnicos de Administração que estão iniciando a sua vida profissional, como um roteiro para o trabalho que irão desenvolver:"

Por outro lado, o autor adverte que "o livro pretende dos estudantes uma tomada de consciência dos problemas de organização e que a obra não se destina a formar organizadores". 0 próprio leitor deve decidir quem tem razão. Ninguém ficará decepcionado com o primeiro volume do Manual de organização. E uma pena que até agora não tenham sido traduzidos os demais volumes, especialmente o segundo (set. 1973). Esta obra é bem diferente das demais analisadas ultimamente nesta seção da RAE. Realmente trata-se de um volume muito condensado, que lembra, de certa maneira, o livro Industriebetriebslehre für Ingenieure de Egon Voss do Hanser Verlag, Munique. É possivelmente a maneira européia de ensinar produção, que não consta com este nome nos currículos das escolas de administração do velho continente. Bem diferente portanto de Buffa, Mayer, Starr, Maynard etc., menos no conteúdo total do que na apresentação.

Evidentemente também é distinto do livro Organização e métodos de McDowell dos Passos Miranda (RAE, set. 1973) que encara o assunto sob o prisma da administração mais pública e menos industrial. Um índice permite mostrar onde o livro de François tem a maior ênfase.

Nas conclusões (p. 235), o autor menciona o segundo volume, que "tratará das funções na empresa e dos imperativos económicos e humanos de uma organização que empenha o trabaIho na busca de uma produtividade acrescida". Portanto, o que faltar neste volume pode ser esperado como parte do segundo.

Por outro lado, o autor não faz concessões no sentido de facilitar a leitura; ele mantém a precisão matemática onde tal é necessário, e o tradutor só transformou os francos franceses em cruzeiros.

Alguns capitulos têm anexos, e a bibliografía é apresentada por capítulo, não pelo livro todo (é necessário esperar o volume 2). No fim de cada capítulo existe um resumo muito bom. Infelizmente não há índice analítico (vamos esperar a tradução do volume 2 antes de criticar isso definitivamente). Eis o indice:

1. Histórico $11 \mathrm{p}$.

2. Características do trabalho $8 \mathrm{p}$.

3. Fisiologia do trabalho $27 \mathrm{p}$.

4. Princípios gerais de organização $10 \mathrm{p}$.

5. Estudos dos tempos $23 \mathfrak{p}$.

6. Simplificação do trabalho $25 \mathrm{p}$.

7. A preparação do trabalho $32 \mathrm{p}$.

8. A regulação do trabalho $20 \mathrm{p}$.

9. A organização das fábricas $25 \mathrm{p}$.

10. Os trabalhos administrativos - 1. a parte: $13 \mathrm{p}$.

$$
\text { estudo e simplificação }
$$

11. Os trabalhos administrativos - 2. a parte:

Os documentos e o material $16 \mathrm{p}$. 
12. Higiene e segurança do trabalho $22 \mathrm{p}$.

\section{Conclusões $2 p$.}

Torna-se necessário, para entender bem o índice, o que de importante $e$ interessante $o$ autor consegue reunir em tão poucas páginas, bem impressas e ilustradas.

$\mathrm{Na}$ p. 4, o leitor é surpreendido por um papiro (?) ou relevo egípcio no qual se vê um planejamento de remoção de uma estátua, e logo nas p. 6 e 7, há uma simplificação de movimentos de Gilbreth, em 28 quadrinhos com explicações depois uma tabela de Therbligs com os símbolos e abundantes notas na p. 9. No capítulo terceiro da fisiologia do trabaIho trava-se conhecimento das leis gerais da fadiga muscular, da utilização dos músculos e da prevenção da fadiga. $\mathrm{Na} \mathrm{p}$. 28 há referência ao capítulo quinto do segundo volume, quando fala das condições fisiológicas e psicológicas dos trabalhadores. O livro trata do dia de trabalho na França (como afirma o tradutor em nota) e ainda do treinamento nesse mesmo capitulo. A lei do hábito, de Wright, é parte da teoria de aprendizado dos americanos o brasileiro pode estranhar a palavra "hábito".

Finalmente, nesse capítulo, algumas ilustrações explicam bem a adaptação da máquina ao homem, mas neste ponto não há surpresas para quem conhece a literatura norte-americana sobre o assunto; os desenhos parecem idênticos.

- capítulo sobre princípios gerais de organização não apresenta nada de novo; trata-se de uma análise clássica de organização de produção fabril - foIhas de roteiro e a análise dos componentes de um produto.
O capítulo de estudo de tempo é excelente, condensado e contém clara exposição das ol (observações instantâneas), o método da amostragem do trabalho. 0 tradutor, aliás, não eliminou, mas reafirmou as abreviações francesas, contribuindo mais ainda para a assim chamada Salada Alfabética, falando em ETF (escritório técrico das fabricações), EE (escritório de estudos), EM (escritório de métodos) e deixando, então, frases do tipo: "O ETF, que trabalha em colaboração com o EE e o EM comporta em geral duas seções." Será que essas letras vêm da AFNOR (a ABNT francesa)? A PDT (preparação do trabalho) do tradutor certamente ficou complicada, mas o uso de uma tabela tradutora teria sido SDT, simplificação do trabalho.

O sexto capítulo é dedicado à SDT (simplificação do trabalho), introduzido o método do diagnóstico - utilização do operário e o simograma (atividades simultâneas) e, principalmente, como interessante maneira $e$ novidade - a fisiologia do trabalho (bio-engenharia) e sua relação com a simplificação. Há uma ótima tabela de coeficientes de ambiência (temperatura e umidade) e a maneira de como usá-la para a correção dos tempos de trabalho. Melhor ainda, no anexo, o método é aplicado num exemplo.

o capítulo 7 é dedicado à preparação do trabalho (PDT) e apresenta um resumo bem condensado, tendo no primeiro anexo exposição clara do método do caminho crítico. A tradução dá a entender que o autor usa - método do caminho crítico sob o nome de PERT, o que pode produzir confusão com o verdadeiro CPM (critical path method) contra o PERT (program evaluation and research task). 0 terceiro anexo é curto e muito instrutivo: preparação rápida dos trabalhos de manutenção. A regulação do trabalho consta do oitavo capítulo, e corresponde mais ou menos ao nosso PCP (planejamento e controle da produção). 0 planejamento recebe o nome francês (?) de planning, palavra esta que arrepia os cabelos de todo bom gaulês, pois é um anglicismo. Anexo a este capítulo, uma rápida noção de controle estatístico, que, em cinco páginas, pouca coisa de útil pode oferecer.

Os capítulos 9, 10 e 11 são dedicados à organização das fábricas, trabalhos administrativos (TA) I e II. Edifícios, movimentação de materiais, manutenção, suprimentos e almoxarifado, de tudo o autor tenta falar nas poucas páginas sobre organização. 0 estudo do TA demonstra clara e exaustivamente os diversos tipos de gráficos em uso para a análise de seqüência de documentos e menciona, rapidamente, a informática. Documentos, fichas, cartões IBM, máquinas de calcular e classificação de documentos completam a segunda parte do TA. Infelizmente, apesar de toda síntese, estes capítulos, não satisfazem, são superficiais demais; destinar-seiam melhor a iniciantes, não a administradores, propriamente; mas, note-se, só estes três ca- 137 pítulos. Portanto, um pequeno senão.

O livro termina com um satisfatório capítulo de higiene e segurança do trabalho - passando inclusive pela escala de ruidos, pelas cores de paredes (dinâmica de cores), até a análise da iluminação e do ar do ambiente. Resumindo: uma ótima introdução condensada na administração do trabalho fabril. Pode-se recomendar muito o li- 
vro, especialmente a administradores práticos. Só o layout (arranjo ou disposição física) está faltando na apreciação. Um milagre 0 que 0 autor conseguiu colocar em 236 páginas. E, se ao ler a resenha, alguém acredita ter visto parênteses demais - e isso é uma desvantagem do texto original - deve o leitor ficar ciente de que a tradução é ótima e o tradutor merece aplausos por ter evitado galicismos, que costumam subrepticiamente entrar nas traduções de livros franceses. $E$ vamos esperar 0 segundo volume de um ótimo manual.

\section{O negro na civilização brasileira}

Por Arthur Ramos. Rio de Janeiro, Livraria Editora da Casa do Estudante do Brasil, 1971. 252 p. v. 1 (Coleção Arthur Ramos). Reed.

$\mathrm{Na}$ década de 20 exaltava-se a nacionalidade brasileira em reação à ameaça de descaracterização pela onda imigrantista; buscava-se a autenticidade na cultura brasileira. Era a passagem do Brasil rural ao Brasil urbano que se refletia no plano das idéias (o Brasil "autêntico", rural, contraposto ao Brasil "nãoautêntico", urbano, imigrantista). Em decorrência, valorizavase o folclore quase como uma ideologia. Nesse momento, surge 0 interesse estratégico pelo negro enquanto "homem do povo", como expressão de brasilidade, de cultura popular.

Começava a ganhar vulto a antropologia cultural no Brasil, e o conceito de cultura passou a fornecer à intelectualidade brasileira elementos "democráticos", manipuláveis, condicionados historicamente. No que tange ao plano teórico de abordagem do negro brasileiro, a fase era de reação à influência ger- manófila de fins do século passado, tão marcante que transpareceu mesmo através dos estudos rigorosos de Nina Rodrigues. Significava libertação de um quadro de referências meramente biológico e negativo, nãomanipulável, atenuado somente pela miscigenação, contraditoriamente considerada indesejável por constituir entrave ao desenvolvimento nacional - 0 subdesenvolvimento do Pais era até então atribuído à fragilidade racial que resultou do mestiçamento com o negro. Se o "mal" passava a ser localizado na cultura, seria contornável e possivel a redenção do povo brasileiro.

A figura principal dessa época, sem dúvida alguma, é o médico, antropólogo e etnólogo Arthur Ramos. Tendo sido, a principio, muito influenciado pelas interpretações psicanalíticas do problema, formuladas pelo mestre Nina Rodrigues, a partir de certo momento passa a conduzir seus trabalhos nos moldes culturalistas.

A obra de que ora nos ocupamos, $\mathbf{D}$ negro na civilizaçăo brasileira, escrita originalmente em ingles, destinou-se especialmente aos cientistas norte-americanos, na época extremamente carentes de informaçōes precisas sobre a complexa situação do negro na vida brasileira. Por isso os propósitos do livro são introdutórios, gerais. Outras obras do autor completam a análise; esta é esquemática.

Nos primeiros capítulos, Arthur Ramos trata dos aspectos propriamente históricos da escravidão no Brasil, compreendidos entre a introdução do tráfico negreiro e a Abolição, para depois estender-se na abordagem da participação do negro em vários setores importantes da vida nacional. 